\title{
The Effect of Hindsight Bias on Psychiatrists’ Clinical Judgment: A Randomized Controlled Trials
}

\author{
Mohammad Arbabi ${ }^{2}$, Babak Mostafazadeh Davani ${ }^{1}$, Majid Sadeghi Najafabadi², Ali Akbar Nejati Safa ${ }^{2}$, Zaniar Ghazizadeh ${ }^{1}$ and Shakiba \\ Javadi* \\ 'School of Medicine, Tehran University of Medical Sciences, Tehran, Iran \\ ${ }^{2} P$ sychiatry and Psychology Research Center, Roozbeh Hospital, Tehran University of Medical Sciences, Tehran, Iran
}

\begin{abstract}
Objectives: Hindsight bias is inevitable in retrospective peer reviews, especially in medical settings. Psychiatrists are highly at risk of hindsight bias, because of the repeated patient hospitalization and the use of medications with a lot of side effects. The goal of our study was to investigate the effect of hindsight bias on psychiatrists' clinical judgment.

Methods: We conducted our survey in 173 psychiatrists who participated in the congress of scientific society of psychiatrists in Iran in December 2010. A clinical vignette was presented to participants and they reviewed hypothetical cases in which patients with bipolar or psychotic features presented for psychiatric care. We informed two-thirds of the participants that a bipolar or psychotic feature accompanied patients' symptoms (hindsight group) but withheld outcome information from the other participants (control group). Participants were asked to estimate the likelihood of each differential diagnosis.

Results: Responses were compared between groups for suggestions of hindsight bias. The results indicate that hindsight bias plays a role in overestimating likelihood of psychotic disorder in these three groups $(P$ value $<0.05)$. Post-hoc analysis confirmed that this difference arises from difference in perceived probability of psychotic disorder without a significant difference in estimation of likelihood of mood disorder.

Conclusion: Psychiatry just like other specialties is vulnerable to hindsight bias and its consequences, such as inappropriate treatments and unnecessary hospital admissions. Our results indicate that psychiatrist who was informed with psychotic disorders, which its misdiagnosis would result in more adverse outcome, would be more prone to hindsight bias.
\end{abstract}

Keywords: Outcome bias; Psychiatry; Mood disorder; Psychotic disorder

\section{Introduction}

"It's much easier after the event to sort the relevant from the irrelevant signals. After the event, of course, a signal is always crystal clear. We can now see what disaster it was signaling since the disaster has occurred, but before the event it is obscure and pregnant with conflicting meanings" [1].

Hindsight bias, results in an unjustified increase in its perceived predictability, which leads to the famous phrase "of course it's clear." Hindsight bias is not deliberate, but is induced by what one researcher described as "creeping determinism," a process propelled by subconscious desire on the part of the expert to appear knowledgeable, intelligent, and unambiguous [2-5]. This type of bias is almost inevitable in retrospective peer review reports [4], in both medical and nonmedical settings.

In recent years, considerable attention has been focused on diagnostic errors in the area of patient safety [6,7]. Repeated hospitalizations, approximately $40 \%$ of psychiatric inpatient are re-hospitalized within one year of discharge [8], and the numerous side effects of antipsychotic and anti-depressive medications $[9,10]$ demonstrate the importance of proper diagnosis without hindsight bias.

Since psychiatry is more susceptible to such errors, these types of biases may lead to unnecessary admissions, excess therapeutic expenses, and increased side effects resulted from medications. Numerous studies have been conducted to assess the quality and susceptibility to bias in physicians [11-14]. LaBine et al. [15] and LeBourgious et al. [16] investigated whether psychiatrists are also susceptible to hindsight bias in various conditions, knowing about the higher incidence of misdiagnosis in this field. In the first study, the authors surveyed a sample of community residents and asked them to rate the quality of care. Half of the participants were informed if a suicide or homicide occurs shortly after the patients were released from the care. Participants who were informed about this outcome overestimated the likelihood that suicide or violence would occur at the time of the patient's release and observed trends for the hindsight group to rate care as being more frequently negligent [16]. Another study examined whether psychiatrists performing case reviews and estimating the risk of suicide and violence would provide responses suggestive of hindsight bias. The result supported the hypothesis that psychiatrists provided with advance knowledge of an adverse outcome would offer responses suggestive of hindsight bias [16]

The current study sought to evaluate diagnostic errors and related factors in the field of psychiatry, with the notion that reduction of these biases could eventually lead to better patient care and safety. We demonstrated that reporting the occurrence of an outcome consistently

*Corresponding author: Shakiba Javadi, Medical Student, School of Medicine, Tehran University of Medical Sciences, Poursina Street, Tehran, Iran, Tel:+989128128391; Fax: +98351 8203414; E-mail: shakibaa89@gmail.com

Received: May 27, 2017; Accepted: June 13, 2017; Published: June 19, 2017

Citation: Arbabi M, Davani BM, Najafabadi MS, Safa AAN, Ghazizadeh Z et al. (2017) The Effect of Hindsight Bias on Psychiatrists' Clinical Judgment A Randomized Controlled Trial. J Psychiatry 20: 425. doi:10.4172/2378 5756.1000425

Copyright: $\odot 2017$ Arbabi M, et al. This is an open-access article distributed under the terms of the Creative Commons Attribution License, which permits unrestricted use, distribution, and reproduction in any medium, provided the original author and source are credited 
increases its perceived likelihood, and change the psychiatrist's judgment and overestimation is more likely in low diagnosis probabilities.

\section{Methods}

\section{Study design}

This survey was conducted by a group of psychiatrists who participated in the Scientific Society of Psychiatrists Congress in Iran in December 2010. Of the 989 members of this society, 669 psychiatrists participated in the congress.

A clinical vignette with some probable differential diagnosis was designed. Two of these differential diagnoses were selected as the least probable, and the other as the most probable diagnosis based on suggestions of five members of National Psychiatric Board. Schizophrenia and bipolar disorder were the least and most probable diagnosis, respectively.

Participants were divided into three groups. Participants in groups $A$ and $B$ were informed of the definite diagnosis to be the least and most probable diagnoses, suggested by members of the National Psychiatric Board, respectively. Then they were asked to fill out questionnaires to rank more probable diagnoses based on their own interpretation of the case scenario. Participants in group C, the control group, were presented with the scenario without any additional explanations and were asked to rate the likelihood of their probable diagnoses. Subjects devoted 15 minutes to complete each questionnaire.

\section{Instructions}

Demographic data including age, sex, graduation year, clinical experiences, hospital or private practice, and university position were collected. The participants were asked to read the scenario and explain their differential diagnoses and also to evaluate the probability of each diagnosis in the light of the information appearing in the passage. The main part of case description was the same for all the three groups: "A young white male who appears to be in his early 20 s presents to the psychiatric emergency room. The patient is highly agitated and directly threatening; he is throwing his food tray and yelling. He is paranoid about staff poisoning him and appears to be responding to internal stimuli. You have no data or history on this patient, but the patient clearly poses a risk to staff and self. The patient is unable to converse with staff at all".

No additional explanations were provided for the control group participants. However, for (Group A) participants, the scenario was continued as follow: "After six months, the patient was brought back to the hospital and after one month of admission and complementary examinations, is treated as a schizoaffective patient." For participants in (Group B), the final diagnosis was introduced as bipolar disorder.

\section{Statistical analyses}

In the study by Fischoff [15], the probability of the estimates before and after knowing about outcomes were $31 \%$ and $58 \%$ respectively. For calculating the sample size, we used comparison of two proportions formula with a confidence interval of $95 \%$, and the power of the study was $80 \%$. At least 70 participants were estimated in each subexperiment. Data were analyzed and percentages among groups are compared using chi-square test. P values less than 0.05 were considered statistically significant. Analysis of variance (ANOVA) test and posthoc analysis were used for comparison between groups.

\section{Results}

A total of 240 subjects were enrolled in this study. Of these, 173 completed the questionnaire. Table 1 summarizes the basic information of participants. There were no significant differences in the basic demographic characteristics between groups.

Figure 1 shows the frequency of each diagnosis in groups A and $\mathrm{B}$, in which schizoaffective and bipolar disorders were reported as the definite diagnosis in their respective scenarios, and that in group C. Next, we sought to determine if the differences in the frequency of preferred differential diagnosis within different groups were significant (Table 2).

The likelihood of choosing schizoaffective disorder as the diagnosis for the scenario had significant difference between three groups $(\mathrm{P}<0.05)$. Post-hoc analyses revealed that this difference arose from differences between the frequencies in group A and the other groups (Table 3).

Although there was a lower likelihood of choosing bipolar disease within group A than in group B and C, the difference was not statically significant (Figure 1).

Finally, we divided the entire differential diagnoses into two categories, psychotic and non-psychotic disorders (Figure 2). Subsequently, ANOVA was used to compare the frequency of each category between groups. The probability of choosing psychotic disorder as the final diagnosis significantly differed among the three groups $(\mathrm{P}<0.05)$. Post-hoc analysis confirmed that this difference comes from higher frequency of this diagnosis within group A. However, there was no significant difference in the frequency of mood disorder between the three groups.

\section{Discussion and Conclusion}

Our study emphasizes the view that receipt of outcome knowledge affects subject's judgment in the direction predicted by the creeping determinism hypothesis. Our results were in agreement with other studies conducted regarding this issue $[6,17,18]$.

Like other specialties, psychiatry is vulnerable to this bias. One advantage of our study over earlier works is the nature and importance

\begin{tabular}{|c|c|c|c|c|}
\hline Types & Group A & Group B & Group C & $\boldsymbol{P}$ \\
\hline $\begin{array}{c}\text { Number of } \\
\text { participants, } \\
\mathrm{n}(\%)\end{array}$ & 52 & 63 & 58 & - \\
\hline Age, mean & $30.1 \%$ & $36.4 \%$ & $33.5 \%$ & - \\
\hline Male (\%) & $41(80.4 \%)$ & 37 & 42 & 0.5 \\
\cline { 2 - 5 } & & $65 \%$ & $78 \%$ & 0.14 \\
\hline $\begin{array}{c}\text { Faculty } \\
\text { member, } \mathrm{n}(\%)\end{array}$ & $9(17.6 \%)$ & 8 & 14 & 14 \\
\hline $\begin{array}{c}\text { Assistant } \\
\text { professor }\end{array}$ & 9 & $13.3 \%$ & $25 \%$ & 0.26 \\
\hline $\begin{array}{c}\text { Associate } \\
\text { professor }\end{array}$ & 0 & 7 & 12 & - \\
\hline Full professor & 0 & 0 & 0 & - \\
\hline Private, $\mathrm{n}(\%)$ & 9 & 14 & 11 & - \\
\hline & $18.8 \%$ & $23.7 \%$ & $19.6 \%$ & - \\
\hline Hospital & 21 & 19 & 22 & - \\
\hline (Percentage) & $43.8 \%$ & $32.2 \%$ & $39.3 \%$ & - \\
\hline $\begin{array}{c}\text { Both } \\
\text { Percentage) }\end{array}$ & 18 & 26 & 23 & - \\
\hline $\begin{array}{c}\text { Years of clinical } \\
\text { resume, mean }\end{array}$ & 8.31 & 10.1 & 10.37 & 0.27 \\
\hline
\end{tabular}

Table 1: Baseline characteristics of the study participants. 
Citation: Arbabi M, Davani BM, Najafabadi MS, Safa AAN, Ghazizadeh Z, et al. (2017) The Effect of Hindsight Bias on Psychiatrists' Clinical Judgment: A Randomized Controlled Trial. J Psychiatry 20: 425. doi:10.4172/2378-5756.1000425

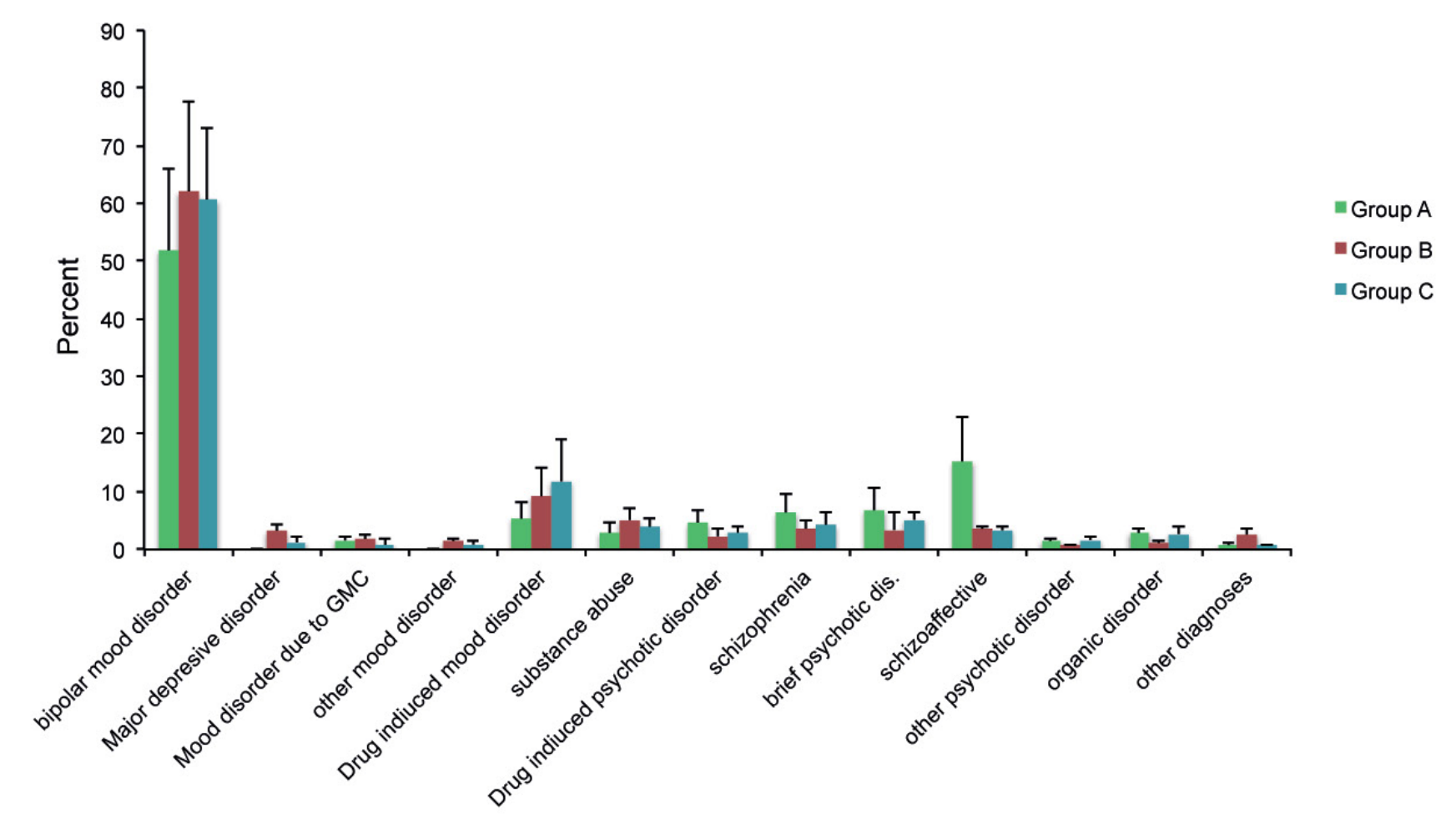

Figure 1: Differential diagnoses and their probabilities in patients in Group A, B and C. Each bar represents mean level of the differential diagnoses. All data are shown as mean \pm S.D. ${ }^{*} p<0.05$

\begin{tabular}{|c|c|c|c|c|c|c|}
\hline Disorders & & Sum of Squares & df & Mean Square & $\mathbf{F}$ & $\mathbf{p}$ \\
\hline \multirow{3}{*}{ Bipolar mood disorder } & Between Groups & 3317.574 & 2 & 1658.787 & \multirow{3}{*}{2.905} & \multirow{3}{*}{0.057} \\
\hline & Within Groups & 97055.559 & 170 & 570.915 & & \\
\hline & Total & 100373.133 & 172 & & & \\
\hline \multirow{3}{*}{ Major depressive disorder } & Between Groups & 291.601 & 2 & 145.8 & \multirow{3}{*}{2.548} & \multirow{3}{*}{0.081} \\
\hline & Within Groups & 9727.232 & 170 & 57.219 & & \\
\hline & Total & 10018.832 & 172 & & & \\
\hline \multirow{3}{*}{ Mood disorder due to GMC } & Between Groups & 34.056 & 2 & 17.028 & \multirow{3}{*}{0.767} & \multirow{3}{*}{0.466} \\
\hline & Within Groups & 3773.424 & 170 & 22.197 & & \\
\hline & Total & 3807.48 & 172 & & & \\
\hline \multirow{3}{*}{ Other mood disorder } & Between Groups & 52.439 & 2 & 26.22 & \multirow{3}{*}{1.407} & \multirow{3}{*}{$0.24 \varepsilon$} \\
\hline & Within Groups & 3167.214 & 170 & 18.631 & & \\
\hline & Total & 3219.653 & 172 & & & \\
\hline \multirow{3}{*}{ Drug induced mood disorder } & Between Groups & 1147.519 & 2 & 573.76 & \multirow{3}{*}{2.443} & \multirow{3}{*}{0.09} \\
\hline & Within Groups & 39929.001 & 170 & 234.876 & & \\
\hline & Total & 41076.52 & 172 & & & \\
\hline \multirow{3}{*}{ Substance abuse } & Between Groups & 140.256 & 2 & 70.128 & \multirow{3}{*}{0.526} & \multirow{3}{*}{0.592} \\
\hline & Within Groups & 22650.46 & 170 & 133.238 & & \\
\hline & Total & 22790.717 & 172 & & & \\
\hline \multirow{3}{*}{ Drug induced psychotic disorder } & Between Groups & 145.47 & 2 & 72.735 & \multirow{3}{*}{0.551} & \multirow{3}{*}{0.578} \\
\hline & Within Groups & 22455.975 & 170 & 132.094 & & \\
\hline & Total & 22601.445 & 172 & & & \\
\hline \multirow{3}{*}{ Schizophrenia } & Between Groups & 244.639 & 2 & 122.319 & \multirow{3}{*}{0.831} & \multirow{3}{*}{0.437} \\
\hline & Within Groups & 25026.633 & 170 & 147.215 & & \\
\hline & Total & 25271.272 & 172 & & & \\
\hline \multirow{3}{*}{ Brief psychotic disorder } & Between Groups & 333.867 & 2 & 166.934 & \multirow{3}{*}{0.929} & \multirow{3}{*}{0.397} \\
\hline & Within Groups & 30540.988 & 170 & 179.653 & & \\
\hline & Total & 30874.855 & 172 & & & \\
\hline
\end{tabular}




\begin{tabular}{|c|c|c|c|c|c|c|}
\hline \multirow{3}{*}{ Schizoaffective } & Between Groups & 5143.357 & 2 & 2571.679 & \multirow{3}{*}{19.395} & \multirow{3}{*}{0} \\
\hline & Within Groups & 22541.498 & 170 & 132.597 & & \\
\hline & Total & 27684.855 & 172 & & & \\
\hline \multirow{3}{*}{ Other psychotic disorder } & Between Groups & 27.455 & 2 & 13.727 & \multirow{3}{*}{0.41} & \multirow{3}{*}{0.665} \\
\hline & Within Groups & 5698.314 & 170 & 33.519 & & \\
\hline & Total & 5725.769 & 172 & & & \\
\hline \multirow{3}{*}{ Organic disorder } & Between Groups & 130.566 & 2 & 65.283 & \multirow{3}{*}{0.732} & \multirow{3}{*}{0.482} \\
\hline & Within Groups & 15156.348 & 170 & 89.155 & & \\
\hline & Total & 15286.913 & 172 & & & \\
\hline \multirow{3}{*}{ Other } & Between Groups & 143.533 & 2 & 71.766 & \multirow{3}{*}{2.604} & \multirow{3}{*}{0.077} \\
\hline & Within Groups & 4684.502 & 170 & 27.556 & & \\
\hline & Total & 4828.035 & 172 & & & \\
\hline
\end{tabular}

Table 2: Comparing differential diagnoses in three sub experiments using ANOVA.

\begin{tabular}{|c|c|c|}
\hline \multirow{2}{*}{ Groups } & \multicolumn{2}{|c|}{ Subset for alpha $=\mathbf{0 . 0 5}$} \\
\cline { 2 - 3 } & 1 & 2 \\
\hline group C $(\mathrm{n}=58)$ & 3.36 & - \\
\hline group B $(\mathrm{n}=63)$ & 3.43 & - \\
\hline group A $(\mathrm{n}=52)$ & - & 15.29 \\
\hline$p$ & 0.975 & 1.000 \\
\hline
\end{tabular}

Table 3: Post hoc analysis of probability of schizoaffective disorder in three groups.

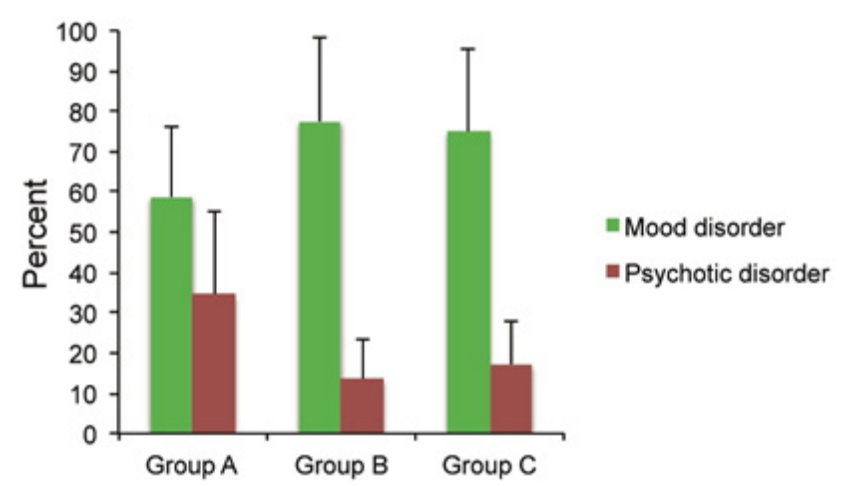

Figure 2: Comparison of estimated probabilities in mood disorder and psychotic disorder between three groups. All data are shown as mean \pm S.D. ${ }^{*} p<0.05$.

of making the correct diagnosis between psychotic and mood disorders, which avoids improper prescription of antipsychotic drugs and inappropriate hospital admission that affects the patient's quality of life.

In our study, (group A) participants, who were given schizoaffective disorder as the definitive diagnosis, estimated the probability of this disorder to be $15.29 \%$, but this disorder was reported at $3.36 \%$ and $3.43 \%$ in (groups B and C), respectively. In other words, reporting an outcome's occurrence consistently increases its perceived likelihood and change psychiatrist's judgment.

On the other hand, (group A) estimated probability of bipolar disorder to be $51.9 \%$, whereas it was estimated to be $61.2 \%$ and $60.6 \%$ in (groups B and C), respectively. Clearly, psychiatrists, who know about the outcome, exaggerate the likelihood estimates through unconscious process, but this difference was not statistically significant.

Our findings suggest that if an outcome is less probable, hindsight bias will be more probable. In other words, schizoaffective disorder, a diagnosis with $3 \%$ probability, increased to $16 \%$ in (group A). These results were supported by the results of Fischoff [17], in which it was found that overestimation is more likely in low probabilities.

According to the study by Croskerry [6], if a person is aware of occurring heuristics, he/she will attempt to prevent its occurrence. Since our study was conducted in a group of psychiatrists, whom it seems are more aware of cognitive bias and heuristics than the others, future studies on the influence of hindsight bias on general practitioners in making definite diagnosis should seek to find a better interpretation of these data. This may be why there was no significant difference between the perceived likelihood of bipolar disorder in three groups. Moreover, in order to prevent bias related to psychiatrists' opinion regarding disease probability for differential diagnoses, we did not present them with a list of diagnoses. However, this method leads to underestimation of probability of some of the less possible diagnoses.

\section{Acknowledgement}

The authors thank all of the participants for their cooperation. This survey was funded by the Education Development Center.

\section{References}

1. Wohlstetter R (1962) Pearl Harbor: Warning and decision. Stanford University Press, US.

2. Baron J, Hershey JC (1988) Outcome bias in decision evaluation. J Pers Soc Psychol 54: 569-579.

3. Berlin L (1996) Malpractice issues in radiology. Perceptual errors. Am J Roentgenol 167: 587-590.

4. Hugh TB, Tracy GD (2002) Hindsight bias in medicolegal expert reports. Med J Aust 176: 277-278.

5. Redelmeier DA (2005) Improving patient care. The cognitive psychology of missed diagnoses. Ann Intern Med 142: 115-120.

6. Croskerry P (2003) The importance of cognitive errors in diagnosis and strategies to minimize them. Acad Med 78: 775-780.

7. Dawson NV, Arkes HR (1987) Systematic errors in medical decision making: Judgment limitations. J Gen Intern Med 2: 183-187.

8. Leape LL (2000) Institute of Medicine medical error figures are not exaggerated. JAMA 284: 95-97.

9. Brennan TA, Leape LL, Laird NM, Hebert L, Localio AR et al. (1991) Incidence of adverse events and negligence in hospitalized patients. Results of the Harvard Medical Practice Study I. N Engl J Med 324: 370-376.

10. Thomas EJ, Studdert DM, Burstin HR, Orav EJ, Zeena T, et al. (2000) Incidence and types of adverse events and negligent care in Utah and Colorado. Med Care 38: 261-271.

11. Arkes HR, Wortmann RL, Saville PD, Harkness AR (1981) Hindsight bias among physicians weighing the likelihood of diagnoses. J Appl Psychol 66: 252-254.

12. Sacchi S, Cherubini $P$ (2004) The effect of outcome information on doctors evaluations of their own diagnostic decisions. Med Educ 38: 1028-1034.

13. Caplan RA, Posner KL, Cheney FW (1991) Effect of outcome on physician judgments of appropriateness of care. JAMA 265: 1957-1960. 
Citation: Arbabi M, Davani BM, Najafabadi MS, Safa AAN, Ghazizadeh Z, et al. (2017) The Effect of Hindsight Bias on Psychiatrists' Clinical Judgment: A Randomized Controlled Trial. J Psychiatry 20: 425. doi:10.4172/2378-5756.1000425

Page 5 of 5

14. Wilson RM, Runciman WB, Gibberd RW, Harrison BT, Newby L, et al. (1995) The quality in Australian health care study. Med J Aust 163: 458-471.

15. Labine SJ, LaBine G (1996) Determinations of negligence and the hindsight bias. Law and Human Behavior 20: 501-516.

16. Lebourgeois HW, Pinals DA, Williams V, Appelbaum PS (2006) Hindsight bias among psychiatrists. J Am Acad Psychiatry Law 35: 67-73.
17. Fischhoff B (2003) Hindsight foresight: The effect of outcome knowledge on judgment under uncertainty. Qual Saf Health Care 12: 304-311.

18. Bornstein BH, Emler AC (2001) Rationality in medical decision making: a review of the literature on doctors' decision making biases. J Eval Clin Pract 7: 97-107. 